\title{
If current inhibition and mortality reduction in heart failure: more than just a 'pure' effect of lowering heart rate
}

\author{
Blokowanie kanałów f a redukcja śmiertelności w niewydolności serca: \\ więcej niż „czysty” efekt obniżenia częstości rytmu serca
}

\section{Piotr Musiałek}

Department of Cardiac and Vascular Diseases, Jagiellonian University Institute of Cardiology, John Paul II Hospital, Krakow, Poland

\section{IF IN THE HEALTHY HEART: SINOATRIAL NODE-LIMITED F-CHANNEL EXPRESSION AND 'PURE' HEART RATE REGULATION}

Cardiac pacemaking is a basic process in health and disease. The If current (often called 'funny' due to its many unusual properties) is an inward mixed $\mathrm{Na}^{+}$and $\mathrm{K}^{+}$current which is activated at negative cell membrane potentials (hence hyperpolarisation-activated) but whose activation causes spontaneous diastolic depolarisation [1]. These If properties are suited to the generation of repetitive electrical activity and the modulation of spontaneous rate [1]. Indeed, the degree of activation of the funny current determines the steepness of spontaneous depolarisation and thus the frequency of spontaneous firing in sino-atrial node (SAN) cells [1]. Because If is controlled by intracellular CAMP and thus is regulated by beta-adrenergic and muscarinic receptor agonists, it mediates the autonomic regulation of heart rate (HR) [1]. Furthermore, independent of autonomic modulation [2, 3], If is regulated by nitric oxide (NO) [4] through an intracellular pathway that involves CGMP and mobilisation of intracellular calcium [5]. The inhibition of endogenous NO production is associated with a reduction in HR both in vitro [6] and in vivo [2, 7], indicating that endogenous $\mathrm{NO}$ exerts a tonic positive chronotropic effect $[2,6]$. Because of the many unusual features of If, it had been queried whether such a large body of properties could correspond to one single current. This was until the If molecular basis became clear with cloning the $f$-channels [8], which confirmed a unique structural basis for this specific membrane current [9]. Under normal physiological conditions, If is functionally expressed exclusively in the SAN cells [1].

Thus the principal publication from SHIfT (Systolic Heart Failure Treatment with the If Inhibitor Ivabradine Trial) in Lancet in 2010 rightly states that: "[beyond If inhibition in
SAN] in healthy hearts (...) ivabradine has no action on other channels in the heart or vascular system" [9].

\section{HUMAN HEART FAILURE: IF IS FUNCTIONALLY EXPRESSED IN VENTRICULAR MYOCYTES}

If is functionally inactive in normal (undiseased) ventricles, both because of very low expression of $f$-channels in the cardiomyocyte membrane and because of too negative, unphysiological voltage range of If activation [1, 10]. Marked upregulation of If expression in the ventricular myocardium, however, has been reproducibly documented in several animal models of heart failure (HF) and in humans suffering from HF in systematic studies of left ventricular (LV) myocytes sampled during cardiac surgery in HF patients [1, 10-12]. Moreover, in myopathic ventricular cells, in the presence of catecholamines, the If activation threshold is shifted towards less negative potentials and thus the current becomes functional at normal diastolic potentials $[11,13]$. In ventricular myocytes, an If-dependent diastolic depolarisation may lead to generation of a propagated action potential — similar to the role played by If in SAN [13]. By favouring spontaneous diastolic depolarisation in myopathic cells, If-generated ectopic 'pacemaker-like' action potentials in the ventricular myocardium provide a mechanism of ventricular arrhythmia $[10,11]$ and arrhythmic death in $\operatorname{HF}[12,13]$.

Thus, in HF the If channel is up-regulated in human ventricular myocardium through its amplified expression [14]. Moreover, in human HF this current also becomes functional at normal potential range and may generate spontaneous diastolic depolarisation in diseased ventricular myocytes, similar to its physiological role in the SAN cells [11-15]. If overexpression and its altered regulation in failing cardiac myocytes (causing, as documented in humans, functional

Address for correspondence:

Piotr Musiałek, MD, DPhil, Department of Cardiac and Vascular Diseases, Jagiellonian University Institute of Cardiology, John Paul II Hospital, ul. Prądnicka 80, 31-202 Kraków, Poland, e-mail: pmusialek@szpitaljp2.krakow.pl

Received: 11.03.2013 r. Accepted: 19.03.2013 r.

Copyright (C) Polskie Towarzystwo Kardiologiczne 
availability of this current in the ventricular myocardium) represents an arrhythmogenic mechanism in $\mathrm{HF}[1,11-15]$.

\section{HEART FAILURE IS ASSOCIATED WITH AN INCREASE IN IF STIMULANTS}

Not only is If functionally expressed in failing LV myocytes [11-15] but also HF is associated with an increase in known If stimulants. Activation of the adrenergic nervous system [16] and increased myocardial NO production [17] are the hallmarks of HF. LV gene expression of constitutive NO synthase increases with the extent of LV dysfunction and the protein level of both (i.e. constitutive and inducible) NO synthases is increased in the failing myocardium [17]. Elevated expression of cardiac inducible NO synthase, as seen in patients with severe $\mathrm{HF}$, attenuates responsiveness to beta-adrenergic stimulation [18], and there is ongoing research into the complexities of NO-dependent molecular mechanisms in HF [19].

To some surprise, in ventricular myocytes in a spontaneously hypertensive rat model, $\mathrm{NO}$ donors or NO synthase inhibition did not alter the amplitude or voltage dependence of If activation [20]. Nevertheless, the rat (in contrast to some other mammalian species) is not an optimal model of human cardiac disease [21] due to several important differences in cardiac myocyte electrophysiology [21-23]. Therefore continued study of human [21, 24] myocardial cells, as in the case of If expression and activation characteristics [10, 11, 14, 15], is of paramount importance in clinical reference to human cardiac pathophysiology [21].

The increased adrenergic tone in $\mathrm{HF}$ is associated, at the SAN level, with HR elevation [25] whereas at the level of the ventricular myocardium, cathecholamines are an established trigger of ventricular arrhythmia [16, 26]. Indeed, sympathetic activation in HF has a profound arrhythmogenic impact [27], and evidence indicates that part of this impact may occur via ventricular myopathic cardiocyte If stimulation [11-15].

\section{IF-DEPENDENT PATHOLOGICAL ELECTRIC ACTIVITY IN VENTRICULAR MYOCYTES IS ABOLISHED BY IF BLOCKADE}

Patch-clamping experiments in failing human ventricular myocytes have revealed that the If current characteristics are consistent with feasibility of its activation in the failing ventricular myocardium and that this effect, as expected, is further promoted by If stimulants [11-15]. The If current blockers (including ivabradine) inhibit the ventricular If channels similar to their mode of action in SAN cells [1].

Ventricular If contribution to the increased risk of malignant ventricular arrhythmias and sudden death in patients with HF, through favouring spontaneous diastolic depolarisation in ventricular myocytes $[1,12,13]$, has been recently mimicked by experimental, forced ectopic expression of If in a normal myocardium using somatic gene transfer (recombinant adenovirus gene carrier) of the 'pacemaker' $f$-channels [28]. Such forced If overexpression in undiseased ventricular myocytes leads to abnormal ventricular automaticity (via spontaneous gradual phase 4 depolarisation that is normally typical of SAN cells) [28]. This abnormal electric activity is enhanced by adrenergic stimulation [28, 29] and is sensitive to pharmacologic inhibition with ivabradine, consistent with a direct, causal role of If [28]. Indeed, If blockers, including ivabradine, have been demonstrated to inhibit ventricular arrhythmias that occur when normal ventricular myocardium is overexpressed with $f$-channels $[28,29]$, mimicking the effect seen with enhanced If expression and its facilitated activation in the ventricular myocardium in HF.

\section{SHIFT DEMONSTRATES REDUCTION OF HEART FAILURE-RELATED MORTALITY WITH IF INHIBITION}

In the recent SHIfT study [9], 6,505 patients with chronic HF were randomised to treatment with the If inhibitor ivabradine or a placebo on top of what was considered standard medical therapy. This study demonstrated that, over a median period of 22.9 months, ivabradine treatment was associated with a significant reduction of the combined endpoint of cardiovascular death or hospital admission for worsening HF (24\% vs. 29\%, $p<0.0001$, primary endpoint of the study) [9]. If inhibition with ivabradine was also associated with a significant reduction of death from HF (3\% vs. 5\%, p $=0.014$, pre-specified secondary endpoint) [9], bringing new focus to the clinical relevance of If modulation in disease states.

Because of the role in normal cardiac electrophysiology, If (and If inhibition) have been commonly associated exclusively with the SAN [9, 30-34]. Thus, analyses of the cardiovascular outcomes in SHIfT have been focused on the magnitude of $\mathrm{HR}$ reduction and suggested (unsurprisingly) that the treatment effect of ivabradine was accounted for by HR reduction [30-33]. As recently found, the therapeutic effect of If blockade in HF was particularly pronounced in patients with baseline $H R \geq 75$ bpm (cutoff indicated by the European Medicines Agency) [33] as in this patient group ivabradine reduced also all-cause mortality (hazard ratio $0.83,95 \% \mathrm{Cl}$ $0.72-0.96, \mathrm{p}=0.011$ ) and cardiovascular mortality (hazard ratio $0.83,95 \% \mathrm{Cl} 0.71-0.97, \mathrm{p}=0.012$ ) [33].

Important beneficial mechanisms related to $\mathrm{HR}$ reduction in HF patients (and also in those with coronary artery disease) and the wider implications of SHIfT have been discussed in detail elsewhere [31-35].

\section{LOWERING HEART RATE: A NON-EXCLUSIVE MECHANISM OF MORTALITY REDUCTION WITH IF INHIBITION IN HEART FAILURE}

Could part of the mortality reduction benefit seen in HF with ivabradine treatment in SHIfT result from inhibition of the 'pacemaker' current If that is known to be functionally expressed [11-15] in the myopathic ventricular myocytes?

Arrhythmic death, unfortunately, was not a pre-specified endpoint in SHIfT [9] and, as it was not evaluated, SHIfT re- 
ports do not include any specific data on arrhythmic death [9]. Therefore there is no level 1 evidence for a clinically-relevant role of ivabradine occurring through inhibition of the abnormal If-dependent spontaneous electric activity in the ventricular myocytes. While it would be theoretically possible (though, given the current guidelines [34, 35], ethically difficult) to design a placebo-controlled arrhythmic death-focused study with If blockade in HF, execution of such a study is highly unlikely also because reliable documentation of arrhythmic death as the study endpoint would require continuous, telemetric ECG monitoring in all study subjects (with the population size and follow-up period exceeding that of SHIfT).

Malignant ventricular arrhythmia such as ventricular tachycardia (VT) or ventricular fibrillation is one of the principal mechanisms of death in $\mathrm{HF}[36,37]$. The presence of non-sustained VT on $24 \mathrm{~h}$ continuous ECG recording increases the odds of dying about three-fold over a 1-2 year follow-up period [36], and ventricular arrhythmia is a documented trigger event in the development of fatal arrhythmia [38]. Unfortunately, history of VT (unless a cardioverter-defibrillator, ICD, was already implanted) or, in those with ICD-ICD shock within six months prior to randomisation, were exclusion criteria from participation in SHIfT [9], minimising a priori the potential of SHIfT to detect the benefit of malignant ventricular arrhythmia suppression occurring through 'ventricular' If inhibition with ivabradine. Despite this important limitation, SHIfT still demonstrated a mortality benefit $[9,33]$, part of which is likely to arise from the action of ivabradine in diseased ventricular myocardium.

Heart failure death was a pre-specified endpoint in SHIfT, and it is well-known that lethal arrhythmias do occur in association with HF worsening [36, 37]. There is evidence that in HF exacerbation [9], a significant proportion of 'pump failure' deaths do overlap with arrhythmic deaths [36]; thus it is often impossible to clearly distinguish one mode of death from the other [36]. One should also take into account that the failing heart undergoes complex electrical remodelling of ventricular myocytes [39], and functional If expression in ventricular myocytes $[10,11,14,15]$ is one of several mechanisms that promote ventricular arrhythmia. Mapping experiments have demonstrated that ventricular arrhythmias in HF are mainly due to non-reentrant mechanisms [38]; an effect consistent with a role of If-dependent abnormal automaticity [12, 13, 15].

Suppression of If-dependent spontaneous abnormal electrical activity in the diseased LV achieved via If inhibition — leading to the mortality reduction with ivabradine in $\mathrm{HF}$ - is an alluring hypothesis that is supported by several lines of patho- and electrophysiological evidence. These lines of evidence include (i) documented functional expression of If in ventricular myocytes in human HF $[10,11,14,15]$, (ii) an HF-associated increase in If stimulants such as the adrenergic drive and myocardial NO production [16-19, 26-27], and (iii) documented ivabradine suppression of abnormal electrical activity associated with If overexpression in the ventricular myocardium [28, 29].
Although analysis of the cardiovascular outcomes in SHIfT [9] has suggested that the treatment effect of ivabradine in $\mathrm{HF}$ is accounted for by $\mathrm{HR}$ reduction $[9,29]$, the degree of $\mathrm{HR}$ reduction with ivabradine is likely to reflect the degree of If inhibition not only in the SAN but also the degree of $f$-channel inhibition in the ventricular myocardium. Thus the widely documented association of the magnitude of clinical benefit of If inhibition with the degree of HR reduction in HF [30-33, 35] is not in any conflict with the contributory effect of If inhibition in ventricular myocytes that leads to malignant automaticity suppression (i.e. the more effective, or the better response to, If inhibition in terms of heart rate reduction magnitude, the more effective is the inhibition of the pathologically expressed If in the myopathic ventricular cells).

In $\mathrm{HF}$, increased $\mathrm{HR}$ is a marker of increased sympathetic activation [25, 40,41], and increased sympathetic activation stimulates malignant ventricular arrhythmias [16, 26] while the functional expression of If in the myopathic ventricular myocytes provides an important arrhythmic mechanism [11-15] that is sensitive to adrenergic stimulation [12-15]. The relative contribution of the two mechanisms (i.e. HR reduction as a result of ivabradine action in the SAN and malignant arrhythmia suppression as a result of ivabradine action in the ventricular myocardium) to the observed mortality reduction $[9,33]$ is impossible to dissociate because pharmacologic If blockers inhibit If both in the SAN and likewise in the failing ventricular myocytes $[1,10,11,14,15,29]$. Thus the HR reduction seen with ivabradine in HF may be, to an extent, an epiphenomenon of the 'ventricular' If inhibition that (also) occurs with ivabradine treatment. For this reason, it is not surprising that (i) in SHIfT patients with baseline HR $\geq 75 \mathrm{bpm}$ (an index of increased sympathetic drive) [25, 40, 41], ivabradine significantly reduced not only HF-related death (hazard ratio $0.61,95 \% \mathrm{Cl} 0.46-0.81, \mathrm{p}<0.001$ ) but also all-cause mortality (hazard ratio $0.83,95 \% \mathrm{Cl} 0.72-0.96, \mathrm{p}=0.011$ ) and cardiovascular mortality (hazard ratio $0.83,95 \% \mathrm{Cl} 0.71-0.97$, $\mathrm{p}=0.012$ ) [33], and (ii) that the primary determinant of study outcomes was, as shown recently, the magnitude of HR reduction by ivabradine combined with beta-blocker, and not the background beta-blocker dose [42].

When taken together, the evidence indicates clearly that part of the therapeutic effect of ivabradine in HF may be associated with the inhibition of the 'pacemaker' current If in the diseased ventricular myocytes. Interestingly, a functional role of the pathological If expression in ventricular myocytes has been proposed [2, 4, 43] following the discovery of a novel If-dependent signalling pathway in the SAN cells [2-4]. Fifteen years later, an overlooked [9] mechanism [1, 11-15] would undoubtedly benefit from its further elucidation in the context of novel data $[9,34]$ that is consistent with a clinical relevance of If that extends beyond heart beat generation and $\mathrm{HR}$ regulation. 


\section{CONCLUSIONS}

While the popular assumption that the action of If inhibitors is limited to the sino-atrial node $[9,34]$ is true for the healthy heart [1], several lines of evidence indicate that this assumption may not hold for the failing human heart [11, 15, 28, 29]. By favouring spontaneous diastolic depolarisation in ventricular myocytes, the If current (which is functionally absent in normal ventricular myocardium but is functionally expressed in human failing cardiomyocytes [11-15]), may contribute to the increased risk of malignant ventricular arrhythmias and death in patients with HF; an effect responsive to If blockade $[28,29]$. Several lines of evidence indicate that part of the mortality reduction seen with ivabradine treatment in SHIfT $[9,33]$ may result from inhibition of the 'pacemaker' current If in the diseased ventricular myocytes. Thus, when it comes to mechanisms behind the recently demonstrated mortality reduction $[9,33]$ in HF patients treated with an If inhibitor, there is likely to be more than just a 'pure' heart rate-lowering effect of the If blockade!

\section{Conflict of interest: none declared}

\section{References}

1. DiFrancesco D. The role of the funny current in pacemaker activity. Circ Res, 2010; 106: 434-446.

2. Musialek P. Nitric oxide and cardiac pacemaking. DPhil Thesis. University of Oxford, Faculty of Clinical Medicine, 1999.

3. Musialek P, Casadei B. Nitrovasodilators and heart rate: More than the arterial baroreflex. Cardiovasc Res, 2000; 47: 404-405.

4. Musialek P, Lei M, Brown HF et al. Nitric oxide can increase heart rate by stimulating the hyperpolarization-activated inward current, If. Circ Res, 1997; 81: 60-68.

5. Musialek P, Rigg L, Terrar DA et al. Role of cGMP-inhibited phosphodiesterase and sarcoplasmic calcium in mediating the increase in basal heart rate with nitric oxide donors. J Mol Cell Cardiol, 2000; 32: $1831-1840$

6. Musialek P, Paterson DJ, Casadei B. Changes in extracellular $\mathrm{pH}$ mediate the chronotropic responses to L-arginine. Cardiovasc Res, 1999; 43: 712-720.

7. Musialek P, Nash M, Thornton J et al. The nitric oxide donor sodium nitroprusside increases heart rate in the absence of changes in arterial blood pressure when applied topically to the sinoatrial node in the anaesthetized pig. J Physiol, 2000; 523: 267-268.

8. Ludwig A, Zong X, Jeglitsch M et al. A family of hyperpolarization-activated mammalian cation channels. Nature, 1998; 393: 587-591.

9. Swedberg K, Komajda M, Böhnm M et al. Ivabradine and outcomes in chronic heart failure (SHIfT): A randomised placebo-controlled study. Lancet, 2010; 376: 875-885.

10. Hoppe UC, Jansen E, Südkamp M et al. Hyperpolarization-activated inward current in ventricular myocytes from normal and failing human hearts. Circulation, 1998; 97: 55-65.

11. Cerbai E, Pino R, Porciatti F et al. Characterization of the hyperpolarization-activated current, If, in ventricular myocytes from human failing heart. Circulation, 1997; 95: 568-571.

12. Biel M, Wahl-Schott C, Michalakis S, Zong X. Hyperpolarization-activated cation channels: From genes to Function. Physiol Rev, 2009; 89: 847-885.

13. Carmeliet E. Cardiac ionic channels and acute ischemia: From channels to arrhythmias. Physiol Rev, 1999; 79: 917-1017.

14. Stillitano F, Lonardo G, Zicha S et al. Molecular basis of funny current (If) in normal and failing human myocardium. J Mol Cell Cardiol, 2008; 45: 289-299.

15. Cerbai E, Sartiani L, DePaoli P et al. The properties of the pacemaker current If in human ventricular myocytes are modulated by cardiac disease. J Mol Cell Cardiol, 2001; 33: 441-448.

16. Esler M, Kaye D, Lambert $\mathrm{G}$ et al. Adrenergic nervous system in heart failure. Am J Cardiol, 1997; 80: 7-14.
17. Umar S, van der Laarse A. Nitric oxide and nitric oxide synthase isoforms in the normal, hypertrophic, and failing heart. Mol Cell Biochem, 2010; 333: 191-201.

18. Drexler H. Nitric oxide synthases in the failing human heart: a double-edged sword? Circulation, 1999; 99: 2972-2975.

19. Michel T. NO way to relax. The complexities of coupling nitric oxide synthase pathways in the heart. Circulation, 2010; 121: 484-486.

20. Bryant SM, Sears CE, Rigg L et al. Nitric oxide does not modulate the hyperpolarization-activated current, If, in ventricular myocytes from spontaneously hypertensive rats. Cardiovasc Res, 2001; 51: 51-58.

21. Rudy Y, Ackerman MJ, Bers DM et al. Systems approach to understanding electromechanical activity in the human heart: a National Heart, Lung, and Blood Institute workshop summary. Circulation, 2008; 118: 1202-1211.

22. Shahid M, Wilson M, Nicholson CD et al. Species-dependent differences in the properties of particulate cyclic nucleotide phosphodiesterase from rat and rabbit ventricular myocardium. J Pharm Pharmacol, 1990; 42: 283-284.

23. Bers DM. Species differences and the role of sodium-calcium exchange in cardiac muscle relaxation. Ann NYAcad Sci, 1991; 639: 375-385.

24. Cohen NM, Lederer WJ. Calcium current in single human cardiac myocytes. J Cardiovasc Electrophysiol, 1993; 4: 422-437.

25. Grassi G, Vailati S, Bertinieri G et al. Heart rate as marker of sympathetic activity. J Hypertens, 1998; 16: 1635-1639.

26. Verrier RL, Antzelevitch C. Autonomic aspects of arrhythmogenesis: the enduring and the new. Curr Opin Cardiol, 2004; 19: 2-11.

27. Schwartz PJ, De Ferrari GM. Sympathetic-parasympathetic interaction in health and disease: Abnormalities and relevance in heart failure. Heart Fail Rev, 2011; 16: 101-107.

28. Xue T, Siu C-W, Lieu DK et al. Mechanistic role of If revealed by induction of ventricular automaticity by somatic gene transfer of gating-engineered pacemaker (HCN) channels. Circulation, 2007; 115: 1839-1850.

29. Plotnikov AN, Bucchi A, Shlapakova I et al. HCN212-channel biological pacemakers manifesting ventricular tachyarrhythmias are responsive to treatment with If blockade. Heart Rhythm, 2008; 5: 282-288.

30. Böhm M, Swedberg K, Komajda M et al. Heart rate as a risk factor in chronic heart failure (SHIfT): The association between heart rate and outcomes in a randomized placebo-controlled trial. Lancet, 2010; 376: 886-894.

31. Kołtowski Ł. Badanie SHIfT - iwabradyna w leczeniu niewydolności serca (in Polish). Kardiol Pol, 2010; 68: 1299-1302.

32. Filipiak KJ. Badanie SHIfT - co nowego wnosi do naszej wiedzy o iwabradynie? (in Polish), Kardiol Pol, 2010; 68: 1303-1304.

33. Böhm M, Borer J, Ford I et al. Heart rate at baseline influences the effect of ivabradine on cardiovascular outcomes in chronic heart failure: analysis from the SHIfT study. Clin Res Cardiol, 2013; 102: 11-22.

34. McMurray JJV, Adamopoulos S, Anker SD et al. ESC Guidelines for the diagnosis and treatment of acute and chronic heart failure 2012. Eur Heart J, 2012; 33: 1787-1874.

35. Kasprzak JD, Stępińska J, Wożakowska-Kapłon B et al. Optimum heart rate - the current goal of cardiovascular therapy. Position statement of the Polish Cardiac Society Working Group on Cardiovascular Drug Therapy. Kardiol Pol, 2012; 70: 1081-1094.

36. Bigger JT. Why patients with congestive heart failure die: arrhythmias and sudden cardiac death. Circulation, 1987; 75: 28-35.

37. Patel J, Heywood JT. Mode of death in patients with systolic heart failure. J Cardiovasc Pharmacol Ther, 2007; 12: 127-136.

38. Kjekshus J. Arrhythmias and mortality in congestive heart failure. Am J Cardiol, 1990; 22: 42-48.

39. Janse MJ. Electrophysiological changes in heart failure and their relationship to arrhythmogenesis. Cardiovasc Res, 2004; 61: 208-217.

40. Barretto AC, Santos AC, Munhoz R et al. Increased muscle sympathetic nerve activity predicts mortality in heart failure patients. Int J Cardiol, 2009; 135: 302-307.

41. Floras JS. Sympathetic nervous system activation in human heart failure: clinical implications of an updated model. J Am Coll Cardiol, 2009; 54: 375-385.

42. Swedberg K, Komajda M, Böhm M et al. Effects on outcomes of heart rate reduction by ivabradine in patients with congestive heart failure: Is there an influence of beta-blocker dose? Findings from the SHIfT (Systolic Heart failure treatment with the If inhibitor ivabradine Trial) study. J Am Coll Cardiol, 2012; 59: 1938-1945.

43. Musiałek P. Role of nitric oxide in heart rate regulation. Kardiol Pol, 2002; 57: 93-98. 